though suggestive, a relationship between tracheomalacia and luetic etiology of the aneurysm cannot be established. The endoscopic treatment with a silicon $\mathrm{T}$ or $\mathrm{T}-\mathrm{Y}$ tube can be effective in resolving this lesion.

\section{References}

1. Maddans M, Pearson FG. Tracheomalacia. In: Pearson FG, editor. Thoracic surgery. New York: Churchill Livingstone; 2002. p. 272-6.
2. Jackman JD Jr, Radolf JD. Cardiovascular syphilis. Am J Med. 1987; $87: 425-33$.

3. Tichonova L, Borisenko K, Ward H, Meheus A, Gromyko A, Renton A. Epidemics of syphilis in the Russian federation: trends, origins, and priorities for control. Lancet. 1997;350:210-3.

4. Cooper JD, Todd TRJ, Ilves R, Pearson FG. Use of the silicone tracheal T-tube for the management of complex tracheal injury. $J$ Thorac Cardiovasc Surg. 1981;82:559-68.

5. Gaissert HA, Grillo HC, Mathisen DJ, Wain JC. Temporary and permanent restoration continuity with tracheal T-tube. $J$ Thorac Cardiovasc Surg. 1994;107:600-6.

\title{
Bronchioloalveolar carcinoma arising from a congenital cystic adenomatoid malformation in an adolescent: The first case report from the Orient
}

Manabu Sudou, MD, ${ }^{a}$ Kazuro Sugi, MD, and Tomoyuki Murakami, MD, ${ }^{\text {b }}$ Yamaguchi, Japan

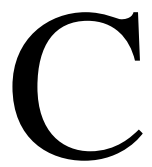

ongenital cystic adenomatoid malformation (CCAM) is an uncommon developmental abnormality of the lung that usually presents in the neonatal period. However, late-onset (over the age of 6 months) CCAM accounts for as much as $17 \%$ of all CCAM cases. Lung cancer arising in CCAM is very rare. Here we report the first case from the Orient of late-onset CCAM associated with lung cancer.

\section{Clinical Summary}

A 17-year-old man was known to have an abnormality on chest radiographs from 10 years earlier. Recently, he had dyspnea on exertion and was diagnosed as having progressive lobar emphysema of the left lower lobe. Chest radiographs showed a lucent area in the lower left lung field and the mediastinum was shifted to the right side (Figure 1). Chest computed tomography showed that the left lower lobe was occupied by huge cystic lesions with no obvious solid component (Figure 2). The patient underwent videoassisted thoracoscopic left lower lobectomy. Macroscopically, multiple cystic lesions were found in the left lower lobe and there was no evidence of a solid tumor. Microscopically, there was an excess of expanded bronchioles and a thick smooth muscle layer in the terminal respiratory structures (Figure 3), and the walls of the cysts were lined by ciliated or columnar cells. These findings were consistent with a diagnosis of type I CCAM according to Stocker's

\footnotetext{
From the Departments of Surgery ${ }^{\mathrm{a}}$ and Clinical Research, ${ }^{\mathrm{b}}$ National Sanyo Hospital, Yamaguchi, Japan.

Received for publication Nov 8, 2002; accepted for publication Jan 7, 2003

Address for reprints: Kazuro Sugi, Higashikiwa 685, Ube, Yamaguchi 755-0241, Japan (E-mail: ksugi@ sanyou.hosp.go.jp).

J Thorac Cardiovasc Surg 2003;126:902-3

Copyright $\odot 2003$ by The American Association for Thoracic Surgery $0022-5223 / 2003 \$ 30.00+0$

doi:10.1016/S0022-5223(03)00397-0
}

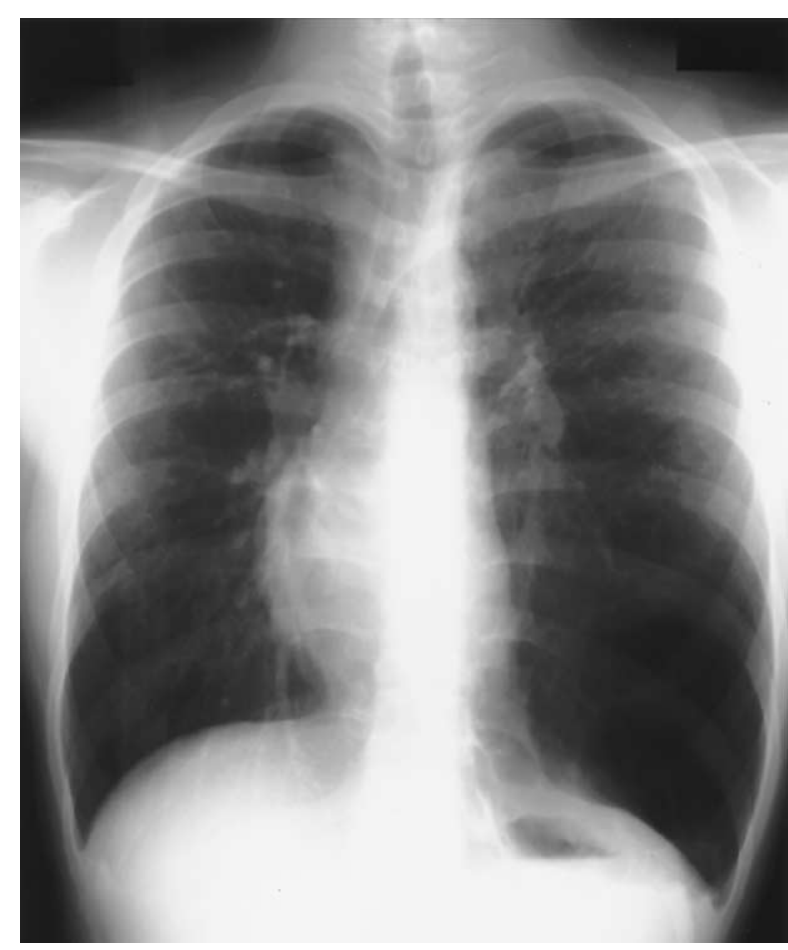

Figure 1. Chest radiograph shows a lucent area in the lower left lung field and the mediastinum shifted to the right side.

classification. In addition, a well-differentiated bronchioloalveolar carcinoma $(3 \times 1 \mathrm{~mm})$ was detected near the hilar side of the cystic lesions without lymphatic or pleural involvement (Figure 4).

The postoperative course was uneventful and the patient was discharged on the 8th postoperative day. He is currently doing well and has no evidence of recurrence or metastasis at 3 months after the operation. 


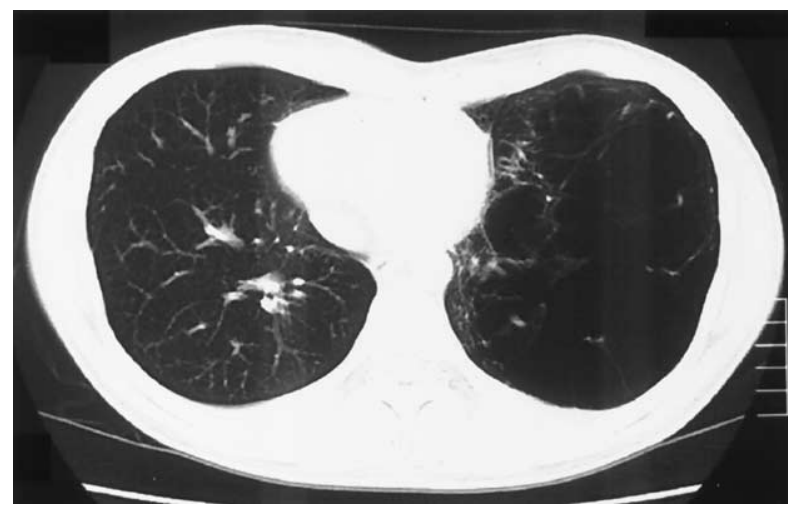

Figure 2. Chest computed tomography show that the left lower lobe was occupied by huge cystic lesions with no obvious solid component.

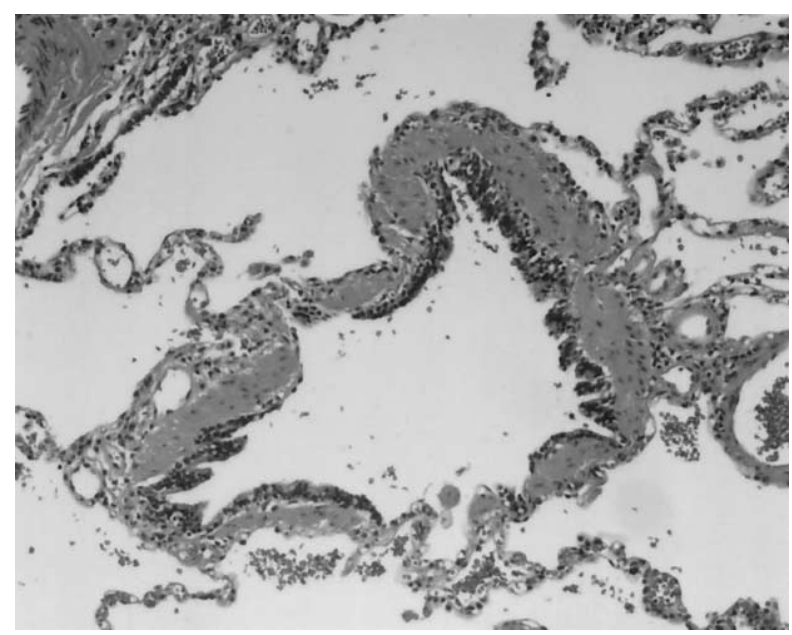

Figure 3. There is an excess of expanded bronchioles with a thick smooth muscle layer in the terminal respiratory structures, corresponding to type I CCAM.

\section{Discussion}

CCAM is an uncommon disease that usually presents in the neonatal period. It is known to be a congenital disorder of pulmonary development, although late-onset CCAM (for example, in a teenager) is occasionally detected. CCAM is classified into 3 types according to the method of Stocker and colleagues. ${ }^{1}$ Many cases of late-onset CCAM are type I, which features large cysts (up to 10 $\mathrm{cm}$ in diameter) and has a good prognosis.

There are only a few reports on CCAM complicated by malignant lung disease. To the best of our knowledge, 8 cases of CCAM associated with lung cancer and 7 cases associated with sarcoma

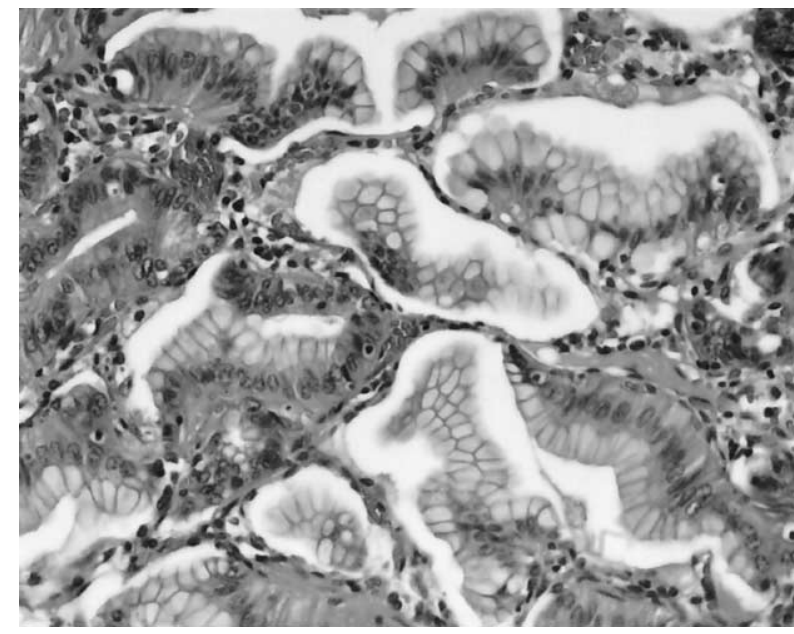

Figure 4. A well-differentiated bronchioloalveolar carcinoma was found near the hilar side of the cystic lesions.

have been reported in the English literature. ${ }^{2,3}$ This is the first report on CCAM associated with lung cancer from the Orient. The prognosis of these reported cases is poor in comparison with that of CCAM patients without malignant lung disease.

The mechanism of lung carcinogenesis in CCAM has not been defined clearly. Cass and coworkers ${ }^{4}$ reported increased cell proliferation and decreased apoptosis in the lungs of CCAM patients. Wang and colleagues ${ }^{5}$ suggested that the glandular component could have the potential for malignant transformation. It is possible that these factors may predispose to the onset of malignancy in CCAM.

All thoracic surgeons have to keep this rare combination of CCAM and malignancy in mind, and lobectomy is recommended as the operative procedure for CCAM so as not to leave behind malignant tissue that might exist among the cystic lesions.

\section{References}

1. Stocker JT, Madwell JE, Darke RM. Congenital cystic adenomatoid malformation of the lung. Hum Pathol. 1977;8:156-71.

2. de Perrot M, Pache JC, Spiliopoulos A. Carcinoma arising in congenital lung cysts. Thorac Cardiovasc Surg. 2001;49:184-5.

3. Ozcan BC, Celik A, Ural Z, Veral A, Kandiloglu G, Balik E. Primary pulmonary rhabdomyosarcoma arising within cystic adenomatoid malformation: a case report and review of the literature. J Pediatr Surg. 2001;36:1062-5.

4. Cass DL, Quinn TM, Yang EY, et al. Increased cell proliferation and decreased apoptosis characterize congenital cystic adenomatoid malformation of the lung. J Pediatr Surg. 1998;33:1043-7.

5. Wang NS, Chen MF, Chen FF. The glandular component in congenital cystic adenomatoid malformation of the lung. Respirology. 1999;4:14753. 